\title{
Coeliac disease and bone mineral density in adult female patients
}

\author{
L R Pistorius, W H Sweidan, D W Purdie, S A Steel, S Howey, J R Bennett, D R Sutton
}

\begin{abstract}
A cross sectional study was undertaken to examine the relationship between coeliac disease and bone mineral density. The 135 female coeliac patients registered on the database of the Department of Gastroenterology at Hull Royal Infirmary were approached by letter, advising them of a potential risk of osteoporosis and inviting them to undergo bone densitometry. A total of 81 registered women $(60 \%)$ attended the Osteoporosis Laboratory, Princess Royal Hospital and underwent dual energy $x$ ray absorptiometry at the lumbar spine (L2-L4) and femoral neck. Historical data relating to the time of diagnosis and adherence to a gluten free diet were obtained. A control group was selected from the local normal population and was first matched for height, weight, and menopausal status. Postmenopausal patients were then further matched to controls of equivalent menopausal age. In coeliac patients, bone mineral density expressed in $\mathrm{g} / \mathrm{cm}^{2}$ as mean (SD) was significantly lower at the lumbar spine $(1.076(0.186))$ than in the control group $(1 \cdot 155(0 \cdot 143), p<0.001)$. This was also the case at the femoral neck $(0.887(0.142)$ versus $0.965(0.127), p<0.001)$. When the coeliac patients were stratified by menopausal status, it was found that femoral neck bone mineral density was significantly below control values in both premenopausal and postmenopausal women. Spinal bone mineral density exhibited a significant decrement only in the postmenopausal group. The age at diagnosis of coeliac disease and adherence to a gluten free diet did not influence bone mineral density at either hip or spine. These results confirm coeliac patients' higher risk of osteopenia. Coeliac disease should be added to the list of medical conditions which constitute an indication for bone densitometry in order that the individual risk of osteoporosis related fracture may be determined.

(Gut 1995; 37: 639-642)
\end{abstract} or idiopathic steatorrhoea and the presence of biochemical derangement of calcium metabolism was noted by Salvesen and Boe ${ }^{2}$ in 40 out of 90 patients with adult sprue. More recently, Harris et $a l^{3}$ comprehensively examined the bone and mineral metabolism of 118 coeliac patients utilising $\mathrm{Ca}^{47}$ balance studies, bone biopsy, and skeletal $x$ ray. Some $63 \%$ of these patients had a significant disturbance of bone metabolism, the most common of which was osteomalacia with or without concomitant osteoporosis, the latter condition being rarely present alone. In a study of 22 treated adult coeliacs, Molteni et al ${ }^{4}$ utilised single photon absorptiometry to measure bone mineral density (BMD) at the distal radius. These patients' BMD values did not differ from those of age matched controls. In 29 untreated adult patients, however, BMD was significantly lower than in age matched controls but did not correlate with the severity of clinical abnormalities. In an intervention study, Caraceni $e t a l^{5}$ noted that, in 20 untreated coeliac adults, $\mathrm{BMD}$ at the distal radius was significantly lower than in age matched controls and that biochemical parameters indicated accelerated bone turnover in the coeliac group. They further observed that 12 months after the institution of a gluten free diet no significant change in BMD had occurred: a result interpreted by these authors as indicating arrest of further bone loss. Equally, no restitution of previously lost bone mass was observed. The basic pathology underlying mineral metabolic derangements in coeliac disease has been well reviewed by Cooke and Holmes. ${ }^{6}$ These workers reported that there is no compelling evidence for excessive excretion of calcium bound to faecal fat and that the basic anomaly is likely to be vitamin $\mathrm{D}$ malabsorption consequent on raised intraluminal $\mathrm{pH}$. Vitamin $\mathrm{D}$ dependent calbindin-D9K is severely depleted in coeliac disease and may mediate calcium malabsorption in this condition. ${ }^{7}$ Calmodulin activity, however, seems to be unchanged. ${ }^{8}$

Taking the opposite tack, Lindh et $a l^{9}$ observed that of 92 patients with proved osteoporosis, $11(12 \%)$ exhibited the presence of antigliadin IgA, a prevalence significantly in excess of that found in the general population. Interestingly, these patients displayed no anomaly of mineral metabolism or calcium malabsorption, and in only three was a histological diagnosis of coeliac disease established. Subclinical coeliac disease thus seemed to be over represented in osteoporotic men and women.

Recently, MacFarlane et al, ${ }^{10}$ using dual energy $x$ ray absorptiometry (DEXA) at hip and spine, found a decrement of BMD at both sites in 50 coeliac patients compared with age and sex matched controls. Butcher et $a l^{11}$ in a
Keywords: coeliac disease, bone, densitometry, osteoporosis.

It has long been recognised that coeliac disease may be associated with disorders of the skeleton. Over 60 years ago Bennett et al ${ }^{1}$ reported major skeletal deformities in patients diagnosed in adult life as having Gee's disease \\ Accepted for publication
}


study of 20 patients concurred that reduced BMD was prevalent in women with coeliac disease and that the detection of osteopenia requires densitometry. In this study, adjustment for body mass index (BMI), dietary control, or disease duration did not affect the overall difference observed between coeliac patients and healthy controls.

The above observations suggest a relationship between coeliac disease and BMD, the latter being the prime determinant of risk of osteoporosis related fracture. ${ }^{12}$ In order to thoroughly examine this relationship we have conducted a study of BMD in coeliac patients with rigorous control for potential confounding variables including menopausal age, BMI, hysterectomy, and exposure to hormone replacement therapy.

\section{Patients and methods}

One hundred and thirty five women, aged 20-70 years, with histologically proved coeliac disease and registered with the Department of Gastroenterology at Hull Royal Infirmary were invited to attend Princess Royal Hospital for densitometric examination of the spine and hip. Eighty one patients $(60 \%)$ attended. After obtaining informed consent, a clinical questionnaire was administered which enquired into the presence of factors known or suspected to influence BMD. These factors included smoking, alcohol use, amount of exercise taken, drug therapy including hormone replacement therapy (HRT) and corticosteroids, or prior hysterectomy. With regard to coeliac disease itself, the time since diagnosis and the degree of adherence to a gluten free diet were also recorded. Weight and height were measured and the BMI was expressed in standard form as weight $(\mathrm{kg})$ divided by height $\left(\mathrm{m}^{2}\right)$.

BMD at the spine (L2-L4) and hip (femoral neck) were measured by DEXA. The apparatus used was the Lunar DPX (Lunar Radiation Corporation, Madison, Wisconsin, USA). Quality assurance studies have shown that in our hands the equipment has a coefficient of variation of $0.78 \%$ for spine and $1 \cdot 2 \%$ for hip BMD.

A matched control was selected for each coeliac patient. The premenopausal controls were selected from 230 healthy women in the third decade, attending for BMD measurement. The postmenopausal controls were selected from our database of values obtained from 6426 women age 50 to 70 . Matching was performed in respect of menopausal status, height, and weight. Postmenopausal patients were then further matched according to the time elapsed since the menopause (menopausal age). Women within 10 years post menopause were matched exactly for menopausal age, women between 10 and 25 years post menopause were matched for menopausal age \pm 2 years, and those over 25 years post menopause were matched for menopausal age \pm 6 years. Each control patient was selected to match the study patient to within $\pm 2 \mathrm{~cm}$ of height and $\pm 2 \mathrm{~kg}$ of weight.
Five patients could not be matched with this precision and were assigned controls whose BMI were within \pm 2.5 of the index case.

Statistical analyses were performed using Epi Info 5.01b (World Health Organization, Geneva, Switzerland) and Kwikstat 2.00 (Texasoft/Mission Technologies, Cedar Hill, Texas, USA). Two sided tests were used with the level of statistical significance set at 0.05 . Parametric variables were compared using the $t$ test (ANOVA and paired $t$ test) and nonparametric variables were compared using the $\chi^{2}$ test, or Fisher's exact test where the numbers were too small to allow accurate interpretation of the $\chi^{2}$ test. Multiple regression analysis was performed to test the effect of BMI, menopausal age, adherence to diet, and duration of coeliac disease on BMD. All values are stated as mean (SD).

The research protocol was approved by the Hull and East Yorkshire Ethics and Clinical Trials Committee.

\section{Results}

Eighty one coeliac disease patients attended for measurement of bone mineral density. Fifty two were premenopausal and 29 postmenopausal. The latter had a mean (SD) age of $59 \cdot 2(8 \cdot 6)$ years with a range of $40-77$ years. There were no differences between coeliac and control groups in respect of hysterectomy, exposure to hormone replacement therapy, corticosteroids, exercise, or tobacco or alcohol consumption (Table I). Age at diagnosis of coeliac disease and institution of a gluten free diet ranged from 0 to 41 years with a median of 8 years. Fifty eight patients reported they had always adhered to a gluten free diet, 17 patients usually adhered, and six patients never adhered. Eighty one matching controls were selected from the normal databases described above. BMD was expressed using the standard area density notation of $\mathrm{g} / \mathrm{cm}^{2}$ presented below as means (SD).

Overall, the coeliac patients $(n=81)$ showed a significantly lower mean (SD) spinal BMD $(1.076(0 \cdot 186))$ than the control group $(1.155$ $(0.143) ; \mathrm{p}<0.001)$. Similarly, BMD at the femoral neck in the coeliac group was 0.887 $(0 \cdot 142)$ whereas that of the control group was $0.965(0.127) ; p<0.001$. When the two groups were stratified according to their menopausal status, the postmenopausal coeliac patients

TABLE I Occurrence of potential confounding variables in coeliac disease patients and control subjects

\begin{tabular}{|c|c|c|c|}
\hline \multirow[b]{2}{*}{ Parameter } & \multicolumn{3}{|l|}{ Group } \\
\hline & Coeliac & Control & Significance \\
\hline \multirow{3}{*}{$\begin{array}{l}\text { Ever smoking } \\
\text { Median (range) alcohol } \\
\text { consumption (U/wk) }\end{array}$} & $44 / 81$ & $49 / 81$ & $\mathrm{NS}^{\star}$ \\
\hline & $2(0-21)$ & $3(0-21)$ & \\
\hline & \multicolumn{3}{|c|}{ Exercise (no): } \\
\hline Athletic & 4 & 3 & $N S^{\star \star}$ \\
\hline Normal & 75 & 78 & $\mathrm{NS}^{\star \star}$ \\
\hline Restricted & 2 & 0 & $\mathrm{NS} \star \star \star$ \\
\hline \multicolumn{4}{|l|}{ Ever use of: } \\
\hline Corticosteroids & $10 / 81$ & $7 / 81$ & $N^{\star} S^{\star}$ \\
\hline HRT & $9 / 29$ & $12 / 29$ & $\mathrm{NS}^{\star}$ \\
\hline Prior hysterectomy & $12 / 29$ & $14 / 29$ & $\mathrm{NS}^{\star}$ \\
\hline
\end{tabular}

${ }^{\star} \chi^{2}$ test; ${ }^{\star \star}$ Fisher's exact test. 
TABLE II Bone mineral density $\left(\mathrm{g} / \mathrm{cm}^{2}\right)$ of the spine (L2-L4) and femoral neck in patients with coeliac disease and their matched normal controls. Values are mean (SD)

\begin{tabular}{|c|c|c|c|}
\hline & \multicolumn{3}{|l|}{ Group } \\
\hline & Coeliac & Control & p Value \\
\hline $\begin{array}{l}\text { Overall: } \\
\text { L2-L4 } \\
\text { Femoral neck }\end{array}$ & $\begin{array}{l}(n=81) \\
1.076(0 \cdot 186) \\
0.887(0.142)\end{array}$ & $\begin{array}{l}(n=81) \\
1 \cdot 155(0 \cdot 143) \\
0.965(0.127)\end{array}$ & $\begin{array}{l}<0.001 \\
<0.001\end{array}$ \\
\hline $\begin{array}{l}\text { Postmenopausal } \\
\text { women: } \\
\text { L2-L4 } \\
\text { Femoral neck }\end{array}$ & $\begin{array}{l}(n=29) \\
0 \cdot 924(0 \cdot 14) \\
0.785(0 \cdot 10)\end{array}$ & $\begin{array}{l}(\mathrm{n}=29) \\
1 \cdot 129(0 \cdot 18) \\
0 \cdot 885(0 \cdot 11)\end{array}$ & $\begin{array}{l}<0.001 \\
<0.001\end{array}$ \\
\hline $\begin{array}{l}\text { Premenopausal } \\
\text { women: } \\
\text { L2-L4 } \\
\text { Femoral neck }\end{array}$ & $\begin{array}{l}(n=52) \\
1 \cdot 160(0 \cdot 151) \\
0.943(0 \cdot 129)\end{array}$ & $\begin{array}{l}(n=52) \\
1 \cdot 169(0 \cdot 117) \\
1.010(0 \cdot 114)\end{array}$ & $\begin{array}{c}\text { NS } \\
<0.001\end{array}$ \\
\hline
\end{tabular}

$(\mathrm{n}=29)$, had a significantly lower spinal BMD of $0.924(0.14)$ than the control value of $1.129(0.70) ; \mathrm{p}<0.001$. In this group, the femoral neck BMD of $0.785(0.72)$ was also significantly below the control group value of 0.885 (0.55); $\mathrm{p}<0.001$.

The premenopausal coeliac patients $(n=52)$ did not show a significantly different spinal BMD (1.160 (0.151)) when compared with their controls $(1 \cdot 169(0 \cdot 117))$. However, at the femoral neck, the premenopausal coeliac patients did show a significantly lower BMD $(0.943(0.129))$ than their controls $(1.010$ $(0 \cdot 114) ; \mathrm{p}<0.01)$ (Table II).

Using multiple regression analysis, neither the time since diagnosis of coeliac disease nor reported adherence to gluten free diet was found to exert any significant influence upon BMD. However, BMI was positively correlated with spinal but not femoral neck BMD. Menopausal age correlated significantly with both spinal and femoral neck BMD (Table III).

\section{Discussion}

This study confirms that coeliac disease adversely affects bone mineral density, and that the relationship holds when female coeliac patients are compared with strictly selected controls matched for sex, height and weight, menopausal status and, where applicable, menopausal age. It can be argued that the premenopausal controls should be age matched too. Published reports are divided about the impact of age as a single factor on BMD in the healthy premenopausal patient, however, ${ }^{13} 14$ and for practical purposes it is generally agreed that peak bone density, achieved in the early third decade is essentially the value with which women later approach the climacteric.

The exact mechanism of the development of osteopenia and osteoporosis in the coeliac patient is incompletely understood. ${ }^{19}$ There is no direct correlation between bone derangements and steatorrhoea, ${ }^{15}$ although the institution of a gluten free diet has been reported to

TABLE III Multiple regression analysis between body mass index (BMI), menopausal age (MEN), adherence to diet $(A D H)$, duration of disease (DUR), and bone mineral density (BMD) of the lumbar spine and femoral neck

\begin{tabular}{llllll}
\hline$B M D$ & $B M I$ & $M E N$ & $A D H$ & DUR & $r^{2}$ \\
\hline L2-L4 & $\mathrm{p}<0.01$ & $\mathrm{p}<0.001$ & NS & NS & 0.45 \\
Femur & NS & $\mathrm{p}<0.001$ & NS & NS & 0.34 \\
\hline
\end{tabular}

have a beneficial effect on BMD. ${ }^{416}$ Possible but unproved mechanisms leading to osteopenia in the coeliac patient include a reduced intestinal surface area due to the characteristic villous atrophy, ${ }^{17}$ saponification of intestinal calcium with unabsorbed fats with increased faecal calcium excretion, ${ }^{6}$ secondary hyperparathyroidism due to reduced absorbtion of calcium, ${ }^{3}$ and decreased absorbtion of vitamin D. ${ }^{18}$

Present lack of understanding of the exact mechanisms involved, makes it difficult to explain our observation that coeliac disease in the premenopausal patient seems to affect the femoral neck BMD alone. This could reflect a differential impact of the calcium/vitamin D malabsorption of coeliac disease on the mainly cortical bone of the femoral neck compared with its effect on the mainly trabecular bone of the lumbar vertebrae. The latter, in the presence of adequate endogenous oestrogen, may be able to maintain $\mathrm{BMD}$ in the face of malabsorption of mineral. After the menopause, the loss of endogenous oestrogen removes the spinal protection and both sites then exhibit substantial decrements on BMD when compared with matched non-coeliac controls. On the other hand, this apparent difference could be artefactual, due to the different populations used for selecting the premenopausal and postmenopausal control groups. We would caution that the use of postal recruitment of a registered coeliac population may incur bias. For example, knowledge that $\mathrm{BMD}$ was to be measured may have encouraged attendance by a sample partially selected by a positive family history of osteoporosis or a previous history of fractures.

What advice should be offered to patients with coeliac disease to protect them against osteoporosis? Although our multiple regression analysis did not show a significant affect of dietary adherence upon BMD, the numbers of non-adherers was small and the true influence of a gluten free diet upon BMD will require to be assessed in a larger, and ideally, prospective study. But consideration should be given to performing bone mineral densitometry either at the time of diagnosis or at the time of menopause, in order to establish basal values of mineral density at the key areas of spine and hip. The premenopausal patient may then be followed up with two repeat densitometry examinations at yearly intervals in order to establish that BMD is stable. Such patients may then be discharged from densitometric follow up until menopause when a further examination will determine if her $\mathrm{BMD}$ requires intervention with HRT or an alternative bone-sparing regime. All postmenopausal patients with coeliac disease should undergo BMD measurement at hip and spine and should be considered for treatment with specific bone-sparing regimens, should a diagnosis of osteoporosis be established.

It should, however, be emphasised that the natural history of bone mineral density in the coeliac patient will remain obscure until prospective studies utilising precise measuring techniques such as DEXA become available. 
For the moment coeliac disease should be added to the list of medical conditions whose presence constitutes an indication for bone densitometry.

1 Bennett TI, Hunter D, Vaughan JM. Idiopathic steatorrhoea (Gee's disease). A nutritional disturbance associated with tetany, osteomalacia and anaemia. $Q \mathcal{X} M$ 1932; 1: 604-77.

2 Salvesen HA, Boe J. Osteomalacia in sprue. Acta Med Scand 1953; 146: 290-9.

3 Harris OD, Warner M, Cooke WT, Pover WFR. Calcium studies in adult coeliac disease and other gastrointestinal conditions with particular reference to osteomalacia. Scand f Gastroenterol 1970; 5: 169-75.

4 Molteni N, Caraceni MP, Bardella MT, Ortolani S, Gandolini GG, Bianchi P. Bone mineral density in adult celiac patients and the effect of gluten-free diet from childhood. Am f Gastroenterol 1990; 85: 51-3.

5 Caraceni MP, Molteni N, Bardella MT, Ortolani S, Nogara A, Bianchi PA. Bone and mineral metabolism in adul celiac disease. Am $\mathcal{f}$ Gastroenterol 1988; 83: 274-7.

6 Cooke WT, Holmes GKT. Clinical presentation. In: Coeliac disease. Edinburgh: Churchill-Livingstone, 1984 90-5.

7 Staun M, Jarnum S. Measurement of the 10000 -molecular weight calcium-binding protein in small-intestinal biopsy specimens from patients with malabsorption syndromes specimens from patients with malabsorptic

8 Amoah J, Williams C, Long RG. Calmodulin content and activity in normal and coeliac duodenum. Gut 1992; 33: 303-6.

9 Lindh E, Ljunghall S, Larsson K, Lavo B. Screening for antibodies against gliadin in patients with osteoporosis.

10 McFarlane X, Bhalla A, Morgan L, Reeves D, Robertson DAF. Osteoporosis: a frequent finding in treated adult coeliac disease. Gut 1992; 33: S48.

11 Butcher GP, Banks LM, Walters JRF. Reduced bone mineral density in coeliac disease - the need for bone densitometry estimations. Gut 1992; 33: S54.

12 Cummings SR, Black DM, Nevitt MC, et al. Bone density at various sites for prediction of hip fractures. Lancet 1993; 341: 72-5.

13 Hansen MA. Assessment of age and risk factors on bone density and bone turnover in healthy premenopausal density and bone turnover in healthy premen

14 Baran DT. Magnitude and determinants of premenopausal bone loss. Osteoporosis International 1994; 4 (suppl 1): S31-4.

15 Moss AJ, Waterhouse C, Terry R. Gluten sensitive enteropathy with osteomalacia but without steatorrhea. $N$ Engl f Med 1965; 272: 825-30.

16 Mora S, Weber G, Barera G, Bellini A, Passolini D, Prinster C, et al. Effect of gluten-free diet on bone mineral conten in growing patients with celiac disease. Am 7 Clin Nut 1993; 57: 224-8.

17 Trier JS. Celiac sprue. New Engl f Med 1991; 325: 1709-19.

18 Thompson GR, Lewis B, Booth CC Absorbtion of vitamin $\mathrm{D}$ in control subjects and patients with intestinal vitamin $D$ in control subjects and patients with in

19 Walters JRF. Bone mineral density in coeliac disease. Gut 1994; 35: 150-1. 